\title{
The First Hominins and the Origins of Bipedalism
}

\author{
William H. E. Harcourt-Smith
}

Published online: 17 August 2010

(C) Springer Science+Business Media, LLC 2010

\begin{abstract}
Molecular and paleontological evidence now point to the last common ancestor between chimpanzees and modern humans living between five and seven million years ago. Any species considered to be more closely related to humans than chimpanzees we call hominins. Traditionally, early hominins have been conspicuous by their absence in the fossil record, but discoveries in the last 20 years have finally provided us with a number of very important finds. We currently have three described genera, Ardipithecus, Orrorin and Sahelanthropus, of which Ardipithecus is extremely well represented by cranial, dental, and postcranial remains. All three genera are argued to be hominins based on reduced canine size and an increased capacity for bipedal locomotion. The evolutionary relationships between these taxa and both earlier hominoids and later hominins are somewhat disputed, but this is to be expected for any species thought to be close to the root of the hominin lineage.
\end{abstract}

Keywords Hominin evolution · Bipedalism · Ardipithecus . Orrorin · Sahelanthropus $\cdot$ Last common ancestor

\section{Introduction}

In the preceding paper, Kieran McNulty (2010) beautifully explains the taxonomic complexities of the Miocene epoch, when numerous ape lineages appeared and disappeared and, in several cases, emerged into those apes that still live

\footnotetext{
W. H. E. Harcourt-Smith $(\square)$

Division of Paleontology, American Museum of Natural History, Department of Anthropology,

Lehman College and Graduate Center, CUNY,

New York, NY, USA

e-mail: willhs@amnh.org
}

today (chimpanzees, gorillas, orangutans, and gibbons). One of those lineages became our own, called the Hominini (or "hominins" colloquially - see the accompanying fact box in Fig. 1 for more explanation). Today modern humans are the only hominin species in existence, but there have been some 20 -odd taxa along the way, and we will certainly find more in the years to come.

As McNulty (2010) also points out, determining what an organism would have looked like at the base of an evolutionary tree is extremely hard. When you find remains from organisms that you suspect sit very near that base, it's hard to know if they lie above or below the branching point that represents the last common ancestor (LCA). Hominins are no exception, and determining the morphology and behavior of the LCA of humans and chimpanzees has become something of an obsession among paleoanthropologists. Cynics might argue that part of the reason for this is that assigning a fossil to the hominin lineage can make a lot of headlines, while sadly just another fossil ape does not.

\section{What Makes a Hominin a Hominin?}

A number of specialized characters define the Hominini. If we compare ourselves to living African apes, we have very large and complex brains for our body size, smaller teeth, and upright walking. We also make very sophisticated tools, engage in complex symbolic and social behaviors, and have language. However, a lot of these are exclusively modern human characteristics and are not much use in defining early hominins. We therefore have to use the fossil record to help us define what features would warrant a fossil specimen hominin status. We also use such fossils to help us reconstruct the likely morphology of the LCA of chimpanzees and humans. As we will see below, current 
Read through enough on human evolution and you will discover that there seems to be a lack of agreement about what to call our own distinct lineage. Because chimps and gorillas are in many ways very similar, it was always thought that they were more closely related to each other than either was to modern humans. Under this taxonomic arrangement, species more closely related to humans than great apes were called hominids. The advent of molecular genetics has forced a rethink. It turns out that a chimpanzee's DNA is more similar to our own than it is to that of gorillas. The result is that chimps and humans form a nested (or monophyletic) group within the broader taxonomic arrangement of apes, to the exclusion of gorillas. Thus a new name was needed for any species more closely related to humans than chimps. We call those creatures hominins, all of whom are extinct except ourselves. Some people still use the term hominids, but it is becoming increasingly obsolete, and educators should be encouraged to use the newer terminology.

Fig. 1 Hominin or hominid?

evidence points to bipedalism occurring very early in the fossil record (Zollikofer et al. 2005; Senut et al. 2001; Lovejoy et al. 2009a), so features relating to that are certainly important. There are a number of other characters that are used as well, and we shall discuss a couple of those briefly before moving on to the actual fossil evidence for early hominins.

\section{Dental Enamel Thickness}

For many years the thickness of the enamel on the cheek teeth (molars and premolars) was used to define whether a specimen was a hominin or not. Humans have thick dental enamel, while the apes closest to us (chimpanzees and gorillas) have thin enamel. The conventional wisdom was that our thick enamel is a reflection of a tougher and more varied diet. However, enamel thickness has become somewhat of a diagnostic problem for hominins. It turns out that a number of Miocene ape species have independently acquired thick enamel, making it a difficult diagnostic trait for exclusive hominin status (Begun 2004).

\section{Loss of the Canine-Premolar Honing Complex}

Another dental characteristic that is used to define hominins is called the canine-premolar honing complex. In chimpanzees, the canine teeth are so big that the distal (or "back") surfaces of the upper canines form an area of contact with the mesial (or "front") surfaces of the third premolars on the lower jaw. These contact areas take the form of very particular wear facets and can be observed on either lower third premolars or upper canines. Their presence therefore indicates animals with relatively large and interlocking canines, which is thought to imply hostile display behaviors between competing males. Reduction in canine size would thus imply a reduction in these behaviors and/or an increase in cooperation between males (Begun 2004). However, as for dental enamel thickness, a number of Late Miocene apes (such as Oreopithecus) also have a reduced or absent canine-premolar honing complex, which might also make this a problematic diagnostic trait (McNulty 2010).

\section{Bipedal Locomotion}

Bipedalism, or upright walking, is argued by many to be the hallmark of being a hominin. Humans are unique among all living primates in the way that they move around. In fact the striding bipedalism that we engage in, where one leg moves in front of the other, is incredibly rare in mammals, and we are the only living member of that group to move in such a way. With such an unusual behavior comes a suite of very particular and specialized anatomical features (see Table 1 for a brief summary). Our skull is balanced directly on top of our spine, a feature that is in part driven by the position and orientation of the foramen magnum (the hole at the bottom of the skull where the spinal cord exits). In humans it is horizontal and anteriorly situated (i.e., toward the face). We have a curved spine and a wide, cup-shaped pelvis, with short iliac blades and a large hip joint. These features facilitate the support of the vertical trunk of the body as well as efficiently transfer weight through to the legs during both standing still and walking or running. Our legs themselves are very long compared to our arms, we have knee joints that can fully extend and lock, and a highly unique foot with a robust ankle region and specialized arches for shock absorption. We have also lost many useful features for climbing, such as an opposable big toe, curved finger and toe bones, and specialist adaptations in the shoulder joint. This loss of arboreal capability is almost as important as the acquisition of specialist bipedal adaptations, as it points to strong directional selection for bipedal locomotion exclusively on the ground (Aiello and Dean 1990; Harcourt-Smith 2007).

By comparison, our closest living relatives, chimpanzees, spend very little time being bipedal. When they do, it is usually postural (e.g., standing up to pick fruit in tall bushes) rather than during actual locomotion. When they move bipedally, it is for very short periods of time and is very inefficient and ungainly. The knees and hips are bent, and there is a strong swaying from side to side. The reason for this is that chimpanzees lack the pelvic morphology and specialist muscle attachments to support the body on the weight-bearing leg during walking. 
Table 1 Table of major features that imply bipedal locomotion (adapted from Harcourt-Smith (2007)

\begin{tabular}{|c|c|}
\hline Anatomical feature & Functional significance \\
\hline $\begin{array}{l}\text { Anteriorly positioned and horizontal } \\
\text { foramen magnum }\end{array}$ & Reflects vertical positioning of spine \\
\hline S-shaped spine & Helps efficiently transfer weight of upright trunk to hip joint \\
\hline Short, curved, and wide iliac blades & Support of upright trunk \\
\hline Wide sacrum & Reflects increased loading on pelvis due to upright trunk \\
\hline Large acetabulum & Increased loading through hip joint \\
\hline Thick inferior neck of femur & Increased loading through hip joint \\
\hline $\begin{array}{l}\text { Femur angles in medially from hip to } \\
\text { knee }\end{array}$ & $\begin{array}{l}\text { Places lower leg closer to midline of body. Helps with balance } \\
\text { when walking on two legs }\end{array}$ \\
\hline Relatively long and robust ankle region & Increases efficiency of foot leverage during walking \\
\hline Arched foot & Shock absorption during walking and running \\
\hline Fully adducted big toe & Efficient weight transfer during toe-off phase of gait cycle \\
\hline
\end{tabular}

Subsequently, they have to keep shifting their weight in order not to topple over (Aiello and Dean 1990; Harcourt-Smith 2007).

In terms of the fossil record, it has long been thought that bipedalism was the first major specialization to have occurred in the hominin lineage. This wasn't always the case. For many years, it was thought that an increase in brain size was the first major evolutionary event to have occurred, but a series of spectacular finds in the 1970s quickly rendered that theory obsolete. First came the discovery of "Lucy" (Johanson et al. 1982), a 3.2-millionyear-old (Ma) Australopithecus afarensis skeleton that was very ape-like above the neck but possessed a suite of characters related to bipedalism throughout the rest of the skeleton. Then came the 3.7-Ma Laetoli footprint trail-an exquisitely preserved moment in time when two or more hominins walked bipedally across an ash-covered landscape (Leakey and Hay 1979). Since the first evidence of brain size increase is not seen until $1.8 \mathrm{Ma}$, it was clear that bipedalism significantly predated this event by well over a million years.

\section{What was the Locomotor Behavior of the Last Common Ancestor?}

One of the central debates concerning the origins of bipedalism involves the locomotor behavior of the LCA of chimps and humans. There have been numerous suggestions, in part due to the historical paucity of the early hominin fossil record. One of the more prevalent theories argues that hominins have a knuckle-walking ancestor, based on observable features in the wrists of chimpanzees, gorillas, and critically, A. afarensis (Richmond and Strait 2000). This theory has since been the subject of some criticism (Dainton 2001; Kivell and Schmitt 2009), and it is important to note that if chimpanzees are more closely related to modern humans than they are to gorillas, then knuckle-walking may have evolved independently in both genera. Alternatively, the last common ancestor of chimpanzees, gorillas, and humans was a knuckle-walker. The problem with that is we have not a single Miocene ape that exhibits any anatomical features definitively relating to knuckle-walking.

Other theories have suggested a wide range of other locomotor repertoires for the LCA, including arboreal bipedalism (Thorpe et al. 2007), generalized terrestrial quadrupedalism (Sarmiento 1998), gibbon-like suspension (Tuttle 1981), and even aquatic swimming and wading behaviors (see Fig. 2: The Aquatic Ape Hypothesis; sink or swim?). As I have noted elsewhere, focusing too much on one particular locomotor behavior for the LCA is a rather polarized way of doing things (Harcourt-Smith 2007; Harcourt-Smith and Aiello 2004). The LCA may have been a rather generalized ape that was capable of engaging in a number of different locomotor behaviors to suit different needs (McHenry 2002). Today's chimpanzees may knuckle-walk, but they are also very good at climbing and engaging in suspensory behaviors. We have to be careful about using chimpanzees as analogues for the LCA, as they may have developed much of their specializations since the chimp-human split, but it's a helpful reminder of the complexities of reconstructing the locomotion of extinct animals (see also Fig. 3: The Missing Link?).

\section{Why Bipedalism?}

Twenty years ago it was easy. The prevalent explanations for why hominins became bidpedal nearly all related to the opening up of savannah grasslands in eastern Africa between 4 and 2 Ma. This was known as the "savannah hypothesis," and in many ways, it made intuitive sense. A less wooded and more open environment necessitated early 
Some educators reading this article will have come across one of the more unusual hypotheses out there relating to the origins of bipedalism. The Aquatic Ape Hypothesis (AAH) suggests that early hominins went through a strong aquatic phase, and that many of the specialist features (such as bipedalism or hairlessness) we see in ourselves today are adaptations to that phase. It's a fun idea, but there is very little evidence to support it. Obviously hominins, like most other animals, always needed to be fairly close to water. Having said that, the water would have been a very dangerous place in Pliocene Africa, with hippos and crocodiles an ever-present and very real threat. It's also hard to imagine the very specialist bipedal features we see in modern humans evolving in an aquatic environment, where precise balance and weight transfer mechanisms are far less important than they would be on land.

Fig. 2 The aquatic ape hypothesis; sink or swim?

hominins to develop strategies to cope with ever more sparsely distributed food and cover. This meant traveling across open savannah from one wooded area to another and that subsequently bipedalism evolved as a more efficient (and quicker) way of getting from A to B. One could then argue that freeing the hands and access to new food resources (e.g., seeds from grasses or animal carcasses from predator kills) acted as a form of positive feedback resulting in further directional selection for features that facilitated bipedal locomotion, as well as scavenging/hunting behaviors and more advanced tool use. Directly relating to the savannah hypothesis, a number of theories tried to explain why hominins became bipedal. Some argued that it was to prevent overheating by exposing less of the body to the overhead sun (Wheeler 1991), others suggested that it developed from postural bipedal feeding behaviours (Hunt 1996) or even that it was simply more efficient than walking on four legs (Rodman and McHenry 1980).

Recent research, though, has caused some serious problems for the savannah hypothesis. Part of this is an

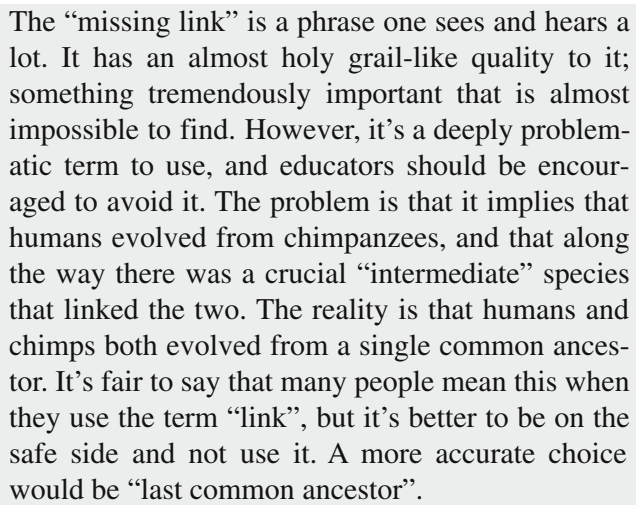

Fig. 3 The missing link? issue of time-depth. Until the 1990s, the oldest definitive hominins were just under $4 \mathrm{Ma}$ in age. In 2010 we have hominins possibly as old as $7 \mathrm{Ma}$. Based on this and also more nuanced paleoecological research, there have been revisions of how the habitat looked at the time. The evidence seems to point to a more closed and wooded environment between 7 and $4 \mathrm{Ma}$, with perhaps a few patches or more open woodland but little in the way of the open savannah we see coinciding with the emergence of the genus Homo sometime between 2 and 3 Ma (Reed 1997; Kingston 2007).

If one takes a closer look at the origins of bipedalism, this isn't necessarily a problem. It is becoming increasingly apparent that its emergence was more complicated than had been thought. In fact early hominins were by no means exclusive (or obligate) bipeds (Harcourt-Smith 2007). We don't see a modern human-like postcranial body plan until the emergence of early Homo at about $1.8 \mathrm{Ma}$. Earlier hominins were capable bipeds, but they also exhibit a suite of skeletal traits indicating regular arboreal climbing behavior. We call those creatures facultative (or habitual) bipeds. The chimp-human LCA was likely only a very occasional biped, and so the shift from that to the facultative bipedalism we see in genera such as Australopithecus occurred when the environment was still quite wooded. The next shift to a modern human-like striding, obligate bipedalism, did however coincide with the opening up of savannah grasslands. It might therefore be possible that bipedalism developed in a number of phases (Harcourt-Smith 2007).

\section{When Did the First Hominins Appear?}

If you take a trip to New York and visit the Hall of Human Origins at the American Museum of Natural History, you will notice that the start of the hall is laid out in two distinct sections. On one side the fossil evidence for human origins is laid out, and panels and displays explain how we find and date fossils. The other side introduces the molecular evidence for human evolution and discusses genetic differences (and similarities) between us and our closest living relatives. Such a design highlights the fact that two major complementary lines of evidence now point to when basal hominins first emerged from a lineage of Miocene apes. An almost exponential increase in the ease of sequencing and analyzing DNA has lead to a rising consensus on the divergence date for the hominin and chimpanzee lineages. Geneticists predict such dates by comparing the differences between the DNA of both species and, assuming a certain rate of genetic change over time, extrapolating back to an approximate date for the LCA. This date is currently estimated at between five and seven million years ago (Ruvolo 1997). Analyses also unequivocally show that 
modern humans and chimps are more closely related to each other than to any other of the living ape species, such as gorillas or orangutans (Ruvolo 1997, and see Fig. 1: "Hominins or Hominids?"). As I have mentioned above, this poses a problem with determining why knucklewalking behavior is seen in both chimpanzees and gorillas. Either it evolved independently in both genera, or it's emergence predates the gorilla-chimp/hominin split, and hominins subsequently lost it.

As we will see below, these molecular dates are now well supported by more and more fossil discoveries from the same time period in eastern and central Africa. Even if one is skeptical about the hominin status of some of these specimens, it stands to reason that hominin contenders are emerging from deposits dating from 4.4 Ma to $7 \mathrm{Ma}$.

\section{Early Contenders}

Prior to the 1990 s, there were very few hominin specimens in the fossil record that were older than about $3.5 \mathrm{Ma}$ in age. Most notable perhaps is a fragmentary mandible from the site of Lothagam in northern Kenya, which was found in the 1960s (Leakey and Harris 2003). It is dated to almost $5 \mathrm{Ma}$, but despite a fair degree of debate, it can only be described as an "indeterminate hominin" at best. This and other extremely meager specimens aside, the "earliest" definitive hominins were considered to be members of the genus Australopithecus, including remains from the wellknown Laetoli and Hadar localities in Tanzania and Ethiopia, respectively. David Strait (2010) deftly deals with this genus (among others) in the next chapter of this special issue.

\section{Enter Ardipithecus}

Complementing the molecular estimates for the humanchimpanzee divergence dates, the last 20 years have heralded major breakthroughs in our understanding of early hominin morphology, behavior, and evolutionary relationships. This is due to a number of major paleontological discoveries dated between four and seven million years ago (see Table 2). We will discuss the possible hominin status of each of them in turn, but the announcement of a new fossil hominin species, Australopithecus ramidus, in 1994 heralded a new chapter in paleoanthropology (White et al. 1994). The specimens were found at the locality of Aramis, in the Middle Awash region of Ethiopia. The dating of the deposits is very accurate at $4.4 \mathrm{Ma}$, based on underlying volcanic ash layers. The joint American-Ethiopian team, led by Tim White (University of California Berkeley), argued that the remains (mainly consisting of teeth, cranial fragments, and a partial ulna) warranted hominin status based on an anteriorly placed foramen magnum, a modified $\mathrm{C} / \mathrm{P} 3$ complex, and the morphology of the proximal ulna (which forms part of the elbow joint). Although the remains were originally named Australopithecus ramidus, the following year White and colleagues (1994) published a correction assigning the species to a new genus, Ardipithecus (White et al. 1995). Their rationale was that newly discovered remains in fact had smaller cheek teeth and thinner tooth enamel than members of the genus Australopithecus. Perhaps the most tantalizing part of the correction, though, was a brief mention of a partial skeleton that had been found near the type specimen. We have had to wait almost 15 years for that skeleton to be further described. Part of the reason for this is that it was incredibly fragmentary and the team had to spend thousands of research hours preparing and conserving it. In the autumn of 2009, a special issue of Science Magazine finally highlighted the skeleton (called ARA-VP-6/500), other craniodental remains, and a wealth of faunal, geological, and paleoecological information, all pertaining to the biology of Ardipithecus ramidus in one way or another.

Between the initial 1994 announcement of Ar. ramidus and the recent description of the skeleton, it should be noted that a second species of Ardipithecus appeared on the scene. Ardipithecus kadabba also harks from Ethiopian fossil-bearing deposits but is considerably older than $\mathrm{Ar}$. ramidus at 5.6-5.8 Ma (Haile-Selassie 2001; Haile-Selassie et al. 2004). The remains mainly consist of teeth and are relatively meager compared to what we have for $A u$. ramidus. Although it also has thin dental enamel, Ar. kadabba is somewhat primitive compared to Ar ramidus, with a larger canine and a more prominent $\mathrm{C} / \mathrm{P} 3$ honing complex. It has also been suggested that Ar. kadabba was capable of bipedalism based on a single toe bone, but more postcranial remains will be needed to support this suggestion.

So what about the Ar. ramidus itself? Dubbed "Ardi," the skeleton described is by far the best-preserved early hominin to date. There are many parts of the skull,
Table 2 Summary information for early hominin species $(\mathrm{Ma}=$ millions of years)

\begin{tabular}{llll}
\hline Taxon & Age range (Ma) & Type Specimen & Type Locality \\
\hline Sahelanthropus tchadensis & $6.8-7.2$ & TM 266-01-060-1 & Toros-Menalla, Chad \\
Orrorin tugenensis & $5.7-6.0$ & BAR 1000'00 & Tugen Hills, Kenya \\
Ardipithecus kadabba & $5.2-5.8$ & ALA-VP-2/10 & Middle Awash, Ethiopia \\
Ardipithecus ramidus & 4.4 & ARA-VP-6/1 & Aramis, Ethiopia \\
\hline
\end{tabular}


including most of the teeth. Below the neck, there is a rather crushed and distorted pelvis, most of the forearm and hands, and most of the lower leg and foot. There is an incomplete femur but sadly, no humerus or scapula, and little in the way of ribs or vertebrae (White et al. 2009a).

There is enough of the skull preserved to allow a reconstruction. This was done "virtually" using highresolution CT scans of the individual fragments, which were then put together on a computer and corrected for distortion. The result has provided some interesting results (Suwa et al. 2009). The cranial capacity is between 300 and 350 cubic centimeters, which is about what we see in modern day chimpanzees. However the face is described as having a mixture of features. The way the face projects outwards is rather chimpanzee-like in the middle part (i.e., around the nose), but much flatter in the lower part (i.e., below the nose and above the front teeth). The base of the skull is rather short at the back, and perhaps most critically, the position of the foramen magnum is argued to be anteriorly placed, as in later hominins. As discussed earlier, this last feature is seen as important in indicating bipedal locomotion.

The postcranial skeleton is fascinating. The arm and hand bones indicate a highly arboreal animal with specialist adaptations to careful climbing in the trees. The authors argue that there are no knuckle-walking features in the wrist and finger bones, meaning that this specialized form of terrestrial quadrupedal locomotion was unlikely in Ardipithecus and its direct ancestors. Rather, they posit that in combination with careful climbing and bridging between branches, Ardipithecus engaged in "above-branch" quadrupedal behaviors, not unlike what has been suggested for the stem ape, Proconsul (Lovejoy et al. 2009b). However, Ardipithecus had an average body weight of 50 kilograms ( $\sim 110$ pounds). Proconsul was a lot lighter, and more work will be needed to try and assess whether such a large animal would have been able to comfortably move quadrupedally along tree branches. The foot also has several characteristics clearly related to arborealism. Most critically it has an opposable hallux (or big toe), which would make it the only hominin with such a primitive feature (Lovejoy et al. 2009c). All other known hominins have lost the ability to grasp with their hallux, indicating a strong shift away from arboreal grasping behaviors.

Where Ardipithecus is really surprising is in the pelvis. The original is highly distorted, but there is some anatomy preserved, and in combination with an elaborate threedimensional reconstruction, it appears that the pelvis shares some features with later hominins (Lovejoy et al. 2009d). Most importantly, the iliac blades appear a little shorter than they do in apes, and there is a structure present called the anterior inferior iliac spine (or AIIS). This is a feature on the anterior (or front) part of the pelvis which indicates a strong attachment for both the iliofemoral ligament, which helps with balance during upright walking, and a muscle that helps fully extend the knee (called rectus femoris).

We therefore have a creature with reduced canines, packed full of climbing-related features that also was capable of some degree of bipedal locomotion. The paleoenvironmental reconstruction of where Ardipithecus lived also points to woodland habitat that is consistent with a predominantly arboreal species (WoldeGabriel et al. 2009; White et al. 2009b). Based on the anatomical findings summarized above, the overall conclusion was that Ardipithecus is an undisputed hominin, albeit one very close to the LCA of chimpanzees and modern humans (White et al. 2009c). As a note of caution, given its recent announcement, many scientists feel that it's still early days with this specimen. Some researchers have even begun to question its hominin status (Harrison 2010; Sarmiento 2010), but we have to wait until more information and full descriptions become available.

\section{Three's a Crowd?}

Just a few years after the arrival of Ar. ramidus on the scene, several other early fossil hominins were discovered and announced and have since heralded a significant amount of argument and debate. First on the scene was Orrorin tugenensis, from the Tugen Hills in central Kenya (Senut et al. 2001). These remains are extremely fragmentary and come from quite a wide geographical area. They are dated to approximately $6 \mathrm{Ma}$, which at the time made them the oldest putative hominin on record. Orrorin is represented by a handful of teeth and several postcranial remains, including a partial femur and humerus. Its discoverers, Martin Pickford and Brigit Senut, argued that it was a hominin based on its thick dental enamel and the morphology of the femur (Senut et al. 2001). They suggested that Orrorin was capable of bipedal locomotion based on a feature, called the obturator externus groove, on the upper part of the femur. They have also argued that the inferior (or lower) part of the femoral neck was disproportionally thick, which has been suggested by some to be a feature that reflects increased downward loading at the hip joint due to upright locomotion. A recent independent statistical analysis of measurements taken from the Orrorin femur has also confirmed it to be very hominin-like and similar in shape to Australopithecus (Richmond and Jungers 2008). Other researchers have noted that a thick inferior femoral neck and obturator externus groove are features only weakly related to bipedal locomotion (Lovejoy et al. 2002). There is also the issue of the Orrorin upper limb remains. There is one highly curved finger bone and a partial humerus with a strong attachment for a muscle 
used in climbing (Senut et al. 2001). Overall, Orrorin could well be a hominin based on its femoral morphology, but if so, it was also a strong climber that was comfortable in the trees. There is also the problem of whether the femur and dental remains actually come from the same species or not. They were found a very long distance from each other, and their association must be treated with some caution.

Not long after Orrorin made the news, another possible species of hominin was announced. Sahelanthropus tchadensis made major headlines around the world and was nicknamed "Toumai" by the press (meaning "Hope of Life" in the local language). The remains were found at the site of Toros-Menalla in Chad, over 2,500 kilometers from the East African Rift Valley (Brunet et al. 2002). They were originally dated to between 6 and 7 Ma based on faunal remains found at the site (Vignaud et al. 2002), but recent geochemical analyses of the sediments have suggested that the dates are closer to $7 \mathrm{Ma}$ (Lebatard et al. 2008). The best-known specimen is a relatively complete cranium (called TM 266-01-060-1). The researchers argued that because it appeared to have a relatively small canine, in combination with a narrow and less prognathic (protruding) face, it must have been a very early hominin. If it is, it's the earliest we have on record. However, the skull is heavily distorted and cracked, which has obscured some important diagnostic characters. The team associated with the find has tried to circumvent this problem by creating a virtual reconstruction of the skull, where they have used computer software and mathematical algorithms to "undistort" it (Zollikofer et al. 2005). The result has two very particular features of note, the position and the angulation of the foramen magnum. In the original, this structure is hard to position, but in the reconstruction its position and angulation are more hominin-like, indicating an affinity for bipedal locomotion. A few more specimens of $S$. tchadensis have also been recovered and seem to indicate intermediate enamel thickness and a non-honing canine - third premolar complex (Brunet et al. 2005).

\section{Conclusions and Context}

Weaving all these various threads of evidence together into something cohesive can be an overwhelming task. Some of the specimens discussed above have only been recently announced, and most of them are still being worked on by the teams that discovered and described them, making it difficult for other researchers to independently assess them. As a result, the evolutionary relationships between these different species are still in a state of flux. Various opinions have thus been expressed, and it really boils down to how one views variation within and between named fossil species. After the announcement of $S$. tchadensis, it was suggested that we were seeing the beginning of major radiation of fossil hominin species and that much more diversity would be uncovered in the years to come (Wood 2002). This could still be the case, but others have suggested that we are overestimating the level of species diversity in early hominin fossils and that Ardipithecus, Sahelanthropus, and Orrorin could very likely all belong to the same genus (White 2003).

In terms of a broader evolutionary context, again, it is still early days. The team that discovered Ardipithecus has suggested that the evidence from Ethiopia and northern Kenya strongly point to a $A r$ r kadabba-Ar. ramidusAustralopithecus anamensis-Au. afarensis "morphocline," an essentially linear sequence of speciation events between 6 and $3 \mathrm{Ma}$ (White et al. 2009c). This is possible, but where Sahelanthropus and Orrorin might fit into the sequence remains to be seen. There is also the issue of $A u$. anamensis, the earliest member of that genus. We find specimens as old as 4.1 Ma from sites in northern Kenya (Leakey et al. 1995), which is only a few hundred thousand years younger than the Ar ramidus remains from Aramis. $A u$. anamensis is very derived both cranially and postcranially compared to Ar. ramidus, and some scholars might find it hard to imagine such a rapid series of evolutionary changes occurring over such a short period of time.

So what can we definitively say about early hominins? We have possibly as many as four species and three genera between 7 and $4.4 \mathrm{Ma}$. Twenty years ago, none of these species had been discovered or named, so we are doing well. The dating of these species coincides very well with the chimpanzee-modern human divergence dates predicted by molecular genetic work. All of them seem to exhibit adaptations to increased levels of bipedalism, but at least two genera (Ardipithecus and Orrorin) would have been very competent climbers as well. We also see a reduction in canine size that might be associated with behavioral shifts in male competition and aggressive threat displays. Finally, and this we can be sure of, the hard work that goes into finding these specimens (in often very remote places) promises many more delights and surprises in the years to come.

\section{References}

Aiello L, Dean C. An introduction to human evolutionary anatomy. London: Academic; 1990.

Begun D. The earliest hominins - is less more? Science. 2004;303: 1478-80.

Brunet M, Guy F, Pilbeam D, Mackaye HT, Likius A, Ahounta D, et al. A new hominid from Upper Miocene of Chad, Central Africa. Nature. 2002;418:145-51.

Brunet M, Guy F, Pilbeam D, Lieberman DE, Likius A, Mackaye HT, et al. New material of the earliest hominid from the Upper Miocene of Chad. Nature. 2005;434:752-5. 
Dainton M. Did our ancestors knuckle-walk? Nature. 2001;410:325-6.

Haile-Selassie Y. Late Miocene hominids from the Middle Awash, Ethiopia. Nature. 2001;412:178-81.

Haile-Selassie Y, Suwa G, White TD. Late Miocene teeth from Middle Awash, Ethiopia, and early hominid dental evolution. Science. 2004;303:1503-5.

Harcourt-Smith WEH. The origins of bipedal locomotion. In: Henke W, Tattersall I, editors. The handbook of paleoanthropology. Dordrecht: Springer; 2007. p. 1483-518.

Harcourt-Smith WEH, Aiello LC. Fossils, feet and the evolution of bipedal locomotion. J Anat. 2004;204:403-16.

Harrison T. Apes among the tangled branches of human origins. Science. 2010;327:532-4.

Hunt KD. The postural feeding hypothesis: an ecological model for the origin of bipedalism. S Afr J Sci. 1996;9:77-90.

Johanson DC, Taieb M, Coppens Y. Pliocene hominids from the Hadar formation, Ethiopia (1973-1977): Stratigraphic, chronologic, and paleoenvironmental contexts, with notes on hominid morphology and systematics. Am J Phys Anthropol. 1982;57:373-402.

Kingston JD. Shifting adaptive landscapes: progress and challenges in reconstructing early hominid environments. Yearb Phys Anthropol. 2007;50(S45):20-58

Kivell TL, Schmitt D. Independent evolution of knuckle-walking in African apes shows that humans did not evolve from a knucklewalking ancestor. PNAS. 2009;106(34):14241-6.

Leakey MG, Harris JM. Lothagam: the dawn of humanity in eastern Africa. New York: Columbia University Press; 2003.

Leakey MD, Hay RL. Pliocene footprints in the Laetoli Beds at Laetoli, northern Tanzania. Nature. 1979;278:317-23.

Leakey MG, Feibel CS, McDougall I, Walker AC. New four-millionyear-old species from Kanapoi and Allia Bay, Kenya. Nature. 1995;376:565-71.

Lebatard A-E, Bourles DL, Durinder P, Jolivet M, Braucher R, Carcaillet J, et al. Cosmogenic nuclide dating of Sahelanthropus tchadensis and Australopithecus bahrelgahazali, Mio-Pliocene hominids from Chads. PNAS. 2008;105(9):3226-31.

Lovejoy CO, Meindl RS, Ohman JC, Heilpe KG, White TD. The Maka femur and its bearing on the antiquity of human walking: applying contemporary concepts of morphogenesis to the human fossil record. Am J Phys Anthropol. 2002;119(2):97-133.

Lovejoy CO, Suwa G, Simpson SW, Matternes JH, White TD. The great divides: the postcrania of our last common ancestors with African apes. Science. 2009a;326:100-6.

Lovejoy CO, Simpson SW, White TD, Asfaw B, Suwa G. Careful climbing in the Miocene: the forelimbs of Ardipithecus ramidus and humans are primitive. Science. 2009b;326:70e1-8.

Lovejoy CO, Latimer B, Suwa G, Asfaw B, White TD. Combining prehension and propulsion: the foot of Ardipithecus ramidus. Science. 2009c;326:72e1-8.

Lovejoy CO, Suwa G, Spurlock L, Asfaw B, White TD. The pelvis and femur of Ardipithecus ramidus: the emergence of upright walking. Science. 2009d;326:71e1-6.

McHenry HM. Introduction to the fossil record of human ancestry. In: Hartwig WC, editor. The primate fossil record. Cambridge: Cambridge University Press; 2002. p. 401-5.

McNulty KP. Apes and tricksters: the evolution and diversification of humans' closest relatives. Evo Edu Outreach. 2010. doi:10.1007/s12052-010-0251-z.

Reed KE. Early hominid evolution and ecological change through the African Plio-Pleistocene. J Hum Evol. 1997;32:289-322.
Richmond BR, Jungers WL. Orrorin tugenensis femoral morphology and the evolution of hominin bipedalism. Science. 2008;319: $1662-5$.

Richmond BG, Strait DS. Evidence that humans evolved from a knuckle-walking ancestor. Nature. 2000;404:382-5.

Rodman PS, McHenry HM. Bioenergetics and the origin of hominid bipedalism. Am J Phys Anthropol. 1980;52:103-6.

Ruvolo M. Molecular hhylogeny of the Hominoids: inferences from multiple independent DNA sequence data sets. Mol Biol Evol. 1997; 14:248-65.

Sarmiento EE. Generalized quadrupeds, committed bipeds and the shift to open habitats: an evolutionary model of hominid divergence. Am Mus Nov. 1998;3250:1-78.

Sarmiento EE. Comment on the paleobiology and classification of Ardipithecus ramidus. Science. 2010;328:1105.

Senut B, Pickford M, Gommery D, Mein P, Kiptalam C, Coppens Y. First Hominid from the Miocene (Lukeino Formation, Kenya). C R Acad Sci Paris. 2001;332:137-44.

Strait D. The evolutionary history of the australopiths. Evo Edu Outreach. 2010. doi:10.1007/s12052-010-0249-6.

Suwa G, Asfaw B, Kono RT, Kubo D, Lovejoy CO, White TD. The Ardipithecus ramidus skull and its implications for human origins. Science. 2009;326:68e1-7.

Thorpe JD, Holder RL, Crompton RH. Origin of human bipedalism as an adaptation for locomotion on flexible branches. Science. 2007;316:1328-31.

Tuttle RH. Evolution of hominid bipedalism and prehensile capabilities. Philos Trans R Soc Lond B. 1981;292:89-94.

Vignaud P, Duringer P, Mackaye HT, Likius A, Blondel C, Boisserie $\mathrm{J}-\mathrm{R}$, et al. Geology and paleontology of the Upper Miocene Toros-Menalla hominid locality, Chad. Nature. 2002;418: $152-5$.

Wheeler PE. The influence of bipedalism on the energy and water budgets of early hominids. J Hum Evol. 1991;21:117-36.

White T. Early hominids - diversity of distortion. Science. 2003;299: 1994-7.

White TD, Suwa G, Asfaw B. Australopithecus ramidus, a new species of early hominid from Aramis, Ethiopia. Nature. 1994;371: 306-12.

White TD, Suwa G, Asfaw B. Australopithecus ramidus, a new species of early hominid from Aramis, Ethiopia-a corrigendum. Nature. 1995;375:88.

White TD, Asfaw B, Beyene Y, Haile-Selassie Y, Lovejoy CO, Suwa $\mathrm{G}$, et al. Ardipithecus ramidus and the paleobiology of early hominids. Science. 2009a;326:75-86.

White TD, Ambrose SH, Suwa G, Su DF, DeGusta D, Bernor RL, et al. Macrovertebrate paleontology and the Pliocene habitat of Ardipithecus ramidus. Science. 2009b;326:8793.

White TD, Asfwa B, Beyene Y, Haile-Selassie Y, Lovejoy CO, Suwa $\mathrm{G}$, et al. Ardipithecus ramidus and the paleobiology of early hominids. Science. 2009c;326:75-86.

WoldeGabriel G, Ambrose SH, Barboni D, Bonnefille R, Bremond L, Currie B, et al. The geological, isotopic, botanical, invertebrate and lower vertebrate surroundings of Ardipithecus ramidus. Science. 2009;326:65e1-5.

Wood B. Hominid revelations from Chad. Nature. 2002;418:133-5.

Zollikofer CPE, Ponce de Leon MS, Lieberman DE, Guy F, Pilbeam D, Likius A, et al. Virtual reconstruction of Sahelanthropus tchadensis. Nature. 2005;434:755-9. 